\title{
O Fundeb como política permanente e a aprovação da Emenda Constitucional $n^{\circ} 108 / 2020$
}

\author{
FUNDEB as a permanent policy and the approval of \\ Constitutional Amendment no. 108/2020
}

\section{Le FUNDEB comme politique permanente et l'approbation de l' \\ "Emenda Constitucional" n. 108/2020.}

\begin{abstract}
Maria Aparecida dos Santos Ferreira ${ }^{1}$ Instituto Federal de Educação, Ciência e Tecnologia do Rio Grande do Norte

Ramon Igor da Silveira Oliveira ${ }^{2}$ Instituto Federal de Educação, Ciência e Tecnologia do Rio Grande do Norte
\end{abstract}

Resumo: Este estudo busca analisar a trajetória do Fundeb e a proposição de um "Novo Fundeb”, estabelecido como política permanente, fundamentando-se em revisão bibliográfica e pesquisa documental. Verificou-se que após aprovações das PECs 15/2015 e 26/2020 na Câmara Federal e no Senado Federal, respectivamente, a Emenda Constitucional $\mathrm{n}^{\circ}$ 108/2020 passou a regular o Fundeb permanente como uma política de Estado, compondo as Disposições Permanentes da Constituição Federal de 1988. A regulamentação do Fundeb em uma lei se faz urgente para que no ano de 2021 se tenham garantidos os recursos para a promoção da educação básica de qualidade socialmente referenciada. Atualmente há dois Projetos de Lei (PL) tramitando no Congresso Nacional, o PL 4.372/2020 e o PL 4.519/2020, na Câmara e no Senado.

Palavras-chave: Fundeb Permanente; Financiamento da educação básica; Emenda Constitucional $n^{\circ} 108 / 2020$.

Abstract: This study aims to analyze the trajectory of Fundeb and the proposal for a "New Fundeb", established as a permanent policy and it is based on a biblographic review and a documentary research. It was found that after the approvals of PECs 15/2015 and 26/2020, in the Federal Chamber and Federal Senate, respectively, the Constitutional Amendment no. 108/2020 began to regulate the permanent Fundeb, as a State policy, composing the Permanent Provisions of the Federal Constitution of 1988. The regulation of Fundeb as a Law is urgent so that in the year of 2021 the resources for the promotion of a basic education of quality socially referenced are guaranteed. Currently there are two Legislative Bills (LB) pending in the National Congress, LB $4.372 / 2020$ and LB 4.519/2020, in the Chamber and Senate.

Keywords: Permanent Fundeb; Financing of basic education; Constitutional amendment no. 108/2020.

\footnotetext{
${ }^{1}$ Doutora em Educação pela Universidade Federal do Rio Grande do Norte. Docente do Instituto Federal de Educação, Ciência e Tecnologia do Rio Grande do Norte, São Paulo do Potengi. E-mail: maria.santos@ifrn.edu.br. Lattes: http://lattes.cnpq.br/2209638083101531. ORCID: https://orcid.org/0000-0002-6213-8916.

${ }^{2}$ Mestrando em Educação Profissional pelo Instituto Federal de Educação, Ciência e Tecnologia do Rio Grande do Norte - IFRN. E-mail: ramonygor@hotmail.com. Lattes: http://lattes.cnpq.br/9367894831287236. ORCID: https://orcid.org/0000-0002-8205-8614.
} 
Revista Educação e Políticas em Debate - v. 10, n. 1, p. 262-279, jan./abr. 2021 - ISSN 2238-8346

Résumé: Cette étude cherche à analyser la trajectoire du Fundeb et la proposition d'un Nouveau Fundeb établi en tant que politique permanente et est fondée sur une révision bibliographique et une recherche documentale. On a vérifié qu'à la suíte des approbations des PECs 15/2015 et 26/2020, dans la Chambre et le Sénat Fédéral, respectivement, l'Emenda Constitucional" n. 108/2020 règle le FUNDEB permanent, et une politique d'État, composant les Dispositions Permanentes de la Constitution Fédérale de 1988. La règlementation du Fundeb comme Loi s'avère urgent pour l'année 2021, il faut qu'on puisse compter sur la promotion de l'éducation de base de qualité socialement référenciée. Actuellement, il y a deux Projets de Loi (PL) qui passent par la procédure administrative dans le Congrès National, le PL 4.519/2020 dans la Chambre et dans le Sénat.

Mots-clés: Fundeb Permanent, Financement de l'éducation de base; "Emenda Constitucional” n. 108/2020.

Recebido em: 20 de outubro de 2020

Aceito em: 19 de novembro de 2020

\section{Introdução}

A educação é reconhecida como um direito social garantido no artigo 208 da Constituição Federal de 1988 (BRASIL, 1988) e no art. $4^{\circ}$ da Lei de Diretrizes e Bases da Educação Nacional (LDB), Lei nº 9.394/96 (BRASIL, 1996). Da educação pública e gratuita a ser ofertada para a população, espera-se um padrão mínimo de qualidade de ensino, intento que só pode ser atingido quando há a disponibilização dos insumos necessários, que se constituem concretamente por meio de espaço físico adequado, materiais didáticos, equipe pedagógica, formação docente inicial e continuada, carreira e remuneração.

Para esse fim, faz-se indispensável o investimento de recursos em suficiente quantidade, conforme a demanda de matrícula, em todos os níveis, etapas e modalidades, tendo em vista a seguridade de tal direito. Esses recursos são fornecidos a partir de mecanismos do financiamento da educação, que se constitui, por sua vez, como "um tipo de política pública e social, uma vez que representa um conjunto sistemático de ações e procedimentos inter-relacionados, politicamente adotados pelos governos dos entes federados com o fim de assegurar o direito social da educação” (BRAGA; SILVA, 2019, p. 3).

De acordo com Cury (2018), não há linearidade na política de financiamento da educação, havendo tanto avanços quanto retrocessos em sua trajetória legal, sendo esses avanços e retrocessos guiados pelo contexto sócio-histórico do momento no qual se encontram. Assim, as principais transformações na estrutura da educação básica brasileira, após a Constituição Federal de 1988, se deram a partir do governo de Fernando Henrique Cardoso (FHC), em 1995, fruto de um plano de gestão fundamentado em ações descentralizadoras e de um ajuste fiscal referenciado nas políticas fundamentadas no neoliberalismo. 
Revista Educação e Políticas em Debate - v. 10, n. 1, p. 262-279, jan./abr. 2021 - ISSN 2238-8346

No referido governo, foi aprovada a Emenda Constitucional (EC) $n^{\circ} 14 / 1996$, que objetivou definir o regime de colaboração e a redistribuição de recursos entre os entes federados. Por outro lado, mesmo essa emenda estabelecendo o papel suplementar da União, manteve a necessidade de explicitação das diretrizes que permitissem operacionalizar o regime de colaboração entre Estados e Municípios quanto à oferta do ensino fundamental.

Essa emenda modificou o art. 60 do Ato das Disposições Constitucionais Transitórias, reduzindo a participação da União na aplicação dos recursos vinculados constitucionalmente, e ampliou as responsabilidades das esferas estaduais e municipais com a criação do Fundo de Manutenção e Desenvolvimento do Ensino Fundamental e de Valorização do Magistério (Fundef) pela Lei n. 9.424/96.

Posteriormente, no governo de Luís Inácio Lula da Silva, foi aprovada a EC $n^{\circ}$ 53/2006, que criou o Fundo de Desenvolvimento da Educação Básica e Valorização dos profissionais da Educação (Fundeb), regulamentado pela Lei n ${ }^{\circ}$ 11.494/2007. Ferreira e Oliveira (2017) explicam que a referida EC incluiu o parágrafo $5^{\circ}$ ao art. 211 da Constituição Federal, afirmando a prioridade para o ensino regular básico. Assim, o Fundeb expandiu a abrangência de atendimento para toda a educação básica, incluindo todas as etapas e modalidades de ensino, redefinindo critérios para a complementação da União, que passa a exercer papel supletivo e participativo no esforço federativo cooperativo. É importante destacar que a complementação da União ao Fundeb, uma das despesas federais mais significativas do setor de educação, não é considerada no cômputo do teto dos gastos.

Considerando que o Fundeb tem vigência até dezembro de 2020, é necessária a aprovação tanto da EC como da lei que o regulamenta. Nesse cenário, a aprovação da EC que transforma o Fundeb em uma política permanente decorreu em meio a muitos debates e embates políticos, em um contexto de crise política, econômica e grave crise sanitária e de pandemia mundial.

Nesse sentido, este estudo busca analisar a trajetória do Fundeb e a proposição de um "Novo Fundeb", estabelecido como política permanente, ressaltando os embates políticos que se deram em seu entorno, desde a proposição da PEC 15/2015 até a aprovação da EC que o instituiu como uma política de Estado.

Metodologicamente, a pesquisa se ancora no materialismo histórico dialético, compreendendo a referida política na realidade concreta e na totalidade dos fatos, debates e embates. Na concepção de Kosik (1976, p. 44), a totalidade significa, "realidade como um todo estruturado, dialético, no qual ou do qual um fator qualquer (classes de fatos, conjuntos de fatos) pode vir a ser racionalmente compreendido".

Assim, a pesquisa fundamenta-se em uma revisão bibliográfica a partir dos estudos de Carnoy (1986), Höfling (2001), Rosa (2003), Calderón, Poltronieri e Borges (2011), Ferreira 
Revista Educação e Políticas em Debate - v. 10, n. 1, p. 262-279, jan./abr. 2021 - ISSN 2238-8346 (2014; 2020), Ferreira e Oliveira (2017), França (2020), Cury (2018), Braga e Silva (2019), Rojo et al. (2019), entre outros estudiosos do financiamento da educação; e, sendo também de cunho documental, utiliza documentos oficiais para apresentar a forma como a política de financiamento da educação se estrutura na perspectiva da política de fundos.

O estudo está organizado em três diferentes tópicos, que analisam a trajetória do Fundeb. No primeiro, são discutidos os conceitos de política de governo e política de Estado, bem como o movimento que o Fundeb faz, enquanto política, entre essas duas categorias; o segundo tópico trata da trajetória da PEC que buscava tornar o Fundeb uma política permanente, bem como do contexto de embates políticos que a envolveram; no último tópico, é abordada a aprovação da Emenda Constitucional que constitui o Fundeb como política de Estado e, por fim, são apresentadas as considerações finais.

\section{O Fundeb permanente como política de Estado}

Na compreensão de Höfling (2001, p. 31), irá configurar-se como Estado o "conjunto de instituições permanentes - como órgãos legislativos, tribunais, exército e outras que não formam um bloco monolítico necessariamente - que possibilitam a ação do governo”. Para a mesma autora, é tido como Governo, por sua vez, o

[…] conjunto de programas e projetos que parte da sociedade (políticos, técnicos, organismos da sociedade civil e outros) propõe para a sociedade como um todo, configurando-se a orientação política de um determinado governo que assume e desempenha as funções de Estado por um determinado período (HÖFLING, 2001, p. 31).

Conforme Carnoy (1986), o Estado e a própria política desencadeiam uma relação intrínseca, a partir da ação legislativa e dos próprios partidos políticos, como fatores decisivos na direção hegemônica do Estado. Essa relação dá origem às políticas públicas que se distinguem em dois diferentes tipos: as políticas públicas de Estado e as políticas públicas de governo (ROJO et al., 2019).

Para Rosa (2003, p. 84), "a noção de Estado contempla a ideia mais ampla de sociedade civil, e a noção de governo, por sua vez, limita-se aos grupos organizados em torno dos partidos políticos". Assim, se organizadas em um nível de hierarquia, seria possível dizer que as políticas de Estado se classificam acima das políticas de governo, uma vez que as primeiras abarcam questões éticas que não permitem a sua substituição ou alteração a partir das mudanças de governo, fazendo-se, assim, permanentes, diferentes das políticas transitórias que se classificam com as de governo (CALDERÓN; POLTRONIERI; BORGES, 2011, p. 818). 
Revista Educação e Políticas em Debate - v. 10, n. 1, p. 262-279, jan./abr. 2021 - ISSN 2238-8346

Dessa forma, ainda que defendam que a dicotomia entre as políticas de Estado e as políticas de governo seja falsa, dado que “toda Política de Governo é uma Política de Estado e, por sua vez, toda Política de Estado é resultado de uma Política de Governo” (p. 817), Calderón, Poltronieri e Borges (2011) admitem que existe uma hierarquia ética entre as políticas permanentes, que visam aos interesses estáticos e universais da sociedade, e as políticas passageiras, que surgem do interesse dos que se encontram politicamente no poder.

Nesse sentido, as lutas em torno do rompimento com a hegemonia dos interesses capitalistas em prol de políticas sociais configuram-se como um grande desafio na busca por garantir políticas duradoras, permanentes, efetivas, dito de outra forma, como políticas de Estado que garantam os direitos sociais (CARNOY, 1986).

O financiamento público da educação teve sua garantia consolidada a partir da Constituição Federal de 1988, que determinou a vinculação de receitas provenientes de impostos para esse fim (BRAGA; SILVA, 2019). Assim, a arrecadação de tributos, dentre os quais encontram-se impostos, taxas e contribuições, tornou-se a principal fonte de recursos responsável pelo financiamento da educação (FERREIRA; OLIVEIRA, 2017). O modelo de arrecadação de impostos definido para o país, porém, é descentralizado (BRAGA; SILVA, 2019), de modo que

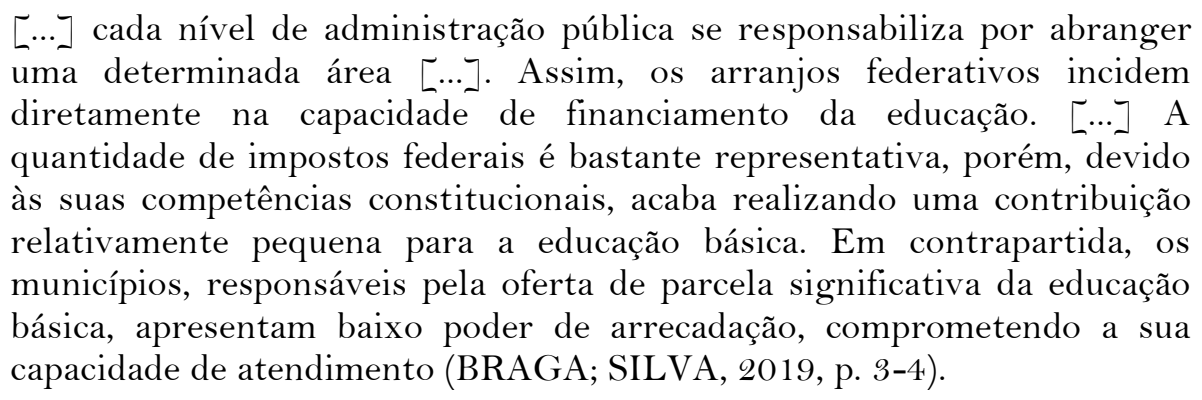

Para Ferreira e Oliveira (2017), esse arranjo descentralizado de financiamento permitiu que os Estados mais ricos, possuintes de um maior poder de arrecadação, possuíssem também uma maior capacidade financeira ao arcar com os custos necessários para proporcionar uma educação pública de qualidade. Em contrapartida, os Estados mais pobres ficavam impedidos de fazer o mesmo.

Desse modo, "a desigualdade entre os entes se tornou bastante evidente, uma vez que a capacidade de cada ente em arrecadar passou a ser diretamente responsável pelo montante de recursos a ser gasto em educação" (BRAGA; SILVA, 2019, p. 4). Nesse contexto de dissemelhança econômica vista entre os Estados e regiões nacionais, passou-se a pensar e discutir maneiras de minimizar essas disparidades. Dessas discussões, surgiu a política de fundos.

A partir das políticas governamentais implementadas pelo Estado, encontram-se os projetos, os programas e as ações de governo que se voltam para esferas particulares da 
Revista Educação e Políticas em Debate - v. 10, n. 1, p. 262-279, jan./abr. 2021 - ISSN 2238-8346 sociedade, como a educação (HÖFLING, 2001). Uma dessas ações é a política de fundos, ocorrida na década de 1990, normatizada pela EC no 14/1996, que criou o Fundef, e posteriormente pela $\mathrm{EC} \mathrm{n}^{\circ}$ 53/2006, que criou o Fundeb. Ambas as políticas tinham como foco permitir "o acesso e a permanência à educação básica, aliado a uma educação de qualidade, bem como à valorização dos profissionais da educação” (FERREIRA, 2014, p. 66).

De acordo com Ferreira (2014), a proposta da política de fundos está firmemente vinculada à política de descentralização fiscal, e busca um melhor e mais eficaz gerenciamento dos recursos. Nesse sentido, o Fundef era constituído a partir da "subvinculação do orçamento da educação advinda dos Estados, Municípios e Distrito Federal, ficando a União encarregada de apenas complementar os Estados onde o Fundo não foi suficiente” (p. 46). O Fundeb, sucessor do Fundef, é um fundo de natureza contábil, transitório, com data de extinção até 31 de dezembro de 2020, fato que o mantém na condição de uma política de financiamento da educação básica com fragilidade institucional.

É importante destacar que a Emenda Constitucional 53/2006 (BRASIL, 2006) criou as quotas municipais do salário-educação $\left(\operatorname{art.~} 212, \S 5^{\circ}\right.$ ) e ampliou a sua aplicação para toda a educação básica (art. 212, $\S 6^{\circ}$ ), bem como criou o Piso Salarial Profissional Nacional (PSPN) (art. 202, inciso VIII), importante avanço na busca pela equalização de oportunidade e de valorização dos profissionais da educação. Além de definir a complementação de no mínimo de $10 \%$ da União para o fundo, vedou a possibilidade do uso do salário-educação para essa complementação e limitou o uso dos recursos vinculados (art. 2012) em, no máximo, 30\% (art. 60 ADCT, incisos V, VII e VIII), definindo ainda que o não cumprimento da complementação da União importa em crime de responsabilidade.

O mais grave da Emenda Constitucional 53/2016 foi a ausência do Custo Aluno Qualidade Inicial (CAQi) em seu texto, uma omissão que se traduz em retrocesso em comparação ao próprio Fundef (PINTO, 2018). A institucionalização do Plano Nacional de Educação (2014-2024), por meio da Lei $n^{\circ}$ 13.005/2014, resgata como necessidade a definição e implementação do Custo Aluno Qualidade inicial (CAQi) ${ }^{3}$, com prazo até junho de 2016, e a definição do Custo Aluno Qualidade (CAQ), até junho de 2017. A partir da redação dada pela EC $n^{\circ}$ 59/2009 ao art. 212, $3^{\circ}$ da Constituição Federal, o financiamento ao ensino obrigatório ( 4 a 17 anos) foi reconhecido como indissociável destes três objetivos: universalização, equidade e qualidade. Infelizmente, a sua regulamentação e implementação ainda não se efetivou.

Assim, o Fundeb é composto por 27 fundos estaduais, os quais proporcionam, em regime de colaboração e redistribuição, recursos financeiros aos diferentes níveis e etapas da

\footnotetext{
${ }^{3}$ Custo Aluno Qualidade Inicial (CAQi) e Custo Aluno Qualidade (CAQ) são concepções desenvolvidas pela campanha; informações atualizadas podem ser encontradas em: FINEDUCA (2020).
} 
Revista Educação e Políticas em Debate - v. 10, n. 1, p. 262-279, jan./abr. 2021 - ISSN 2238-8346 educação básica, ajustados a um custo aluno. Tal ação de colaboração envolve todos os entes federativos do país, uma vez que os recursos são empregados na garantia da política social inscrita como direito de todos e dever do Estado, instituída pela Constituição Federal de 1988. Desse modo, seus recursos pertencem a cada Estado e Município, não havendo personalidade jurídica ou órgão administrativo gestor. Trata-se de um sistema de contas bancárias por meio do qual os recursos são direcionados para atender o objetivo da manutenção da educação básica (FRANÇA, 2020).

Portanto, o Fundeb é um bom exemplo de regime de colaboração a partir da concepção de um federalismo cooperativo ${ }^{4}$, que se efetiva na ação redistributiva entre os entes federados, na descentralização e no compartilhamento das responsabilidades entre as unidades federativas, tendo em vista a oferta de uma educação básica de qualidade.

Nesse sentido, a efetivação do Fundeb traz consequências positivas para todas as redes públicas, visto que garante, a partir da subvinculação de recursos, as perspectivas de valorização dos profissionais da educação através de uma política salarial nacional para os docentes com o Piso Salarial Profissional Nacional associado ao valor aluno/ano, a jornada de trabalho e formação docente, e o mais adequado atendimento aos estudantes da educação básica. Porém, é importante destacar que a vinculação de $60 \%$ destinada para pagamentos de professores, tanto no Fundef como no Fundeb, não corresponde à totalidade dos recursos da educação, e que os gastos com pessoal em educação ultrapassam os $80 \%$ do custo total. Os estudos e as experiências têm mostrado que, apesar de alguns avanços, a política de fundos acabou não promovendo uma valorização profissional, denominação dada tanto no Fundef como no Fundeb para esse fim, principalmente no que se refere à totalidade dos entes federados. A referida valorização ocorreu com raras exceções nos entes federados que, com o Fundeb, passaram a receber a complementação da União (PINTO, 2018).

São características do Fundeb, ainda, a previsão de um controle social mais intenso e estrutural, quando comparado ao antigo Fundef, ampliando a participação e restringindo a intervenção dos Executivos, o que não tem impedido as práticas de desvios dos recursos do Fundeb. Como afirma Pinto (2018, p. 859), "os Conselhos de Acompanhamento e Controle Social (CACS) atuam apenas sobre os recursos do Fundeb, que não correspondem à totalidade dos recursos para a educação e atuam a posteriori, quando as despesas já foram executadas.”

Os recursos do Fundeb são provindos de $20 \%$ da receita de uma variada cesta de impostos, que são: Fundo de Participação dos Estados; Fundo de Participação dos Municípios; Imposto sobre Circulação de Mercadorias e Serviços (ICMS); Imposto sobre Produtos

\footnotetext{
4. O federalismo adotado na Constituição brasileira de 1988 é cooperativo, visto que busca um equilíbrio de poderes entre a União e os Estados-Membros por intermédio da colaboração. Morais (2020, p. 29).
} 
Revista Educação e Políticas em Debate - v. 10, n. 1, p. 262-279, jan./abr. 2021 - ISSN 2238-8346 Industrializados, proporcional às exportações (IPI); Desonerações das Exportações (Lei Kandir) + Dívida Ativa, juros e multas dos impostos; Imposto sobre Transmissão Causa Mortis (ITCM); Imposto sobre Propriedade de Veículos Automotores (IPVA); Imposto Territorial Rural (ITR) devido dos Municípios + Dívida Ativa, juros e multas dos impostos. Dentre os impostos que constituem o Fundeb, o ICMS é aquele que mais arrecada em escala crescente, passando da razão de 76 milhões no ano de 2014 para mais de 90 milhões em 2018 (FRANÇA, 2020).

Sendo uma política de governo, a vigência do Fundeb foi definida para dezembro de 2020, quando deveria vencer e dar espaço a uma nova política de financiamento da educação básica. Porém, a partir da aprovação do Plano Nacional de Educação (2014 a 2024), regulamentado pela Lei $n^{\circ} 13.005 / 2014$, iniciaram-se as proposições de que o fundo deveria se tornar permanente, migrando, assim, para o campo da política de Estado. Tal proposta se justifica pelos prejuízos que a finalização do fundo poderiam acarretar ao financiamento da educação, principalmente no que diz respeito à correção da disparidade econômica entre os Estados e ao cumprimento das metas estabelecidas pelo atual PNE (BRAGA; SILVA, 2019).

Assim, torna-se iminente não apenas a manutenção do Fundeb como política de financiamento da educação básica, mas também a sua aprovação como política permanente, visto o seu papel redistributivo de recursos, que corrige as disparidades financeiras e garante que mesmo os Municípios mais pobres possuam o mínimo necessário para o oferecimento da educação (BRAGA; SILVA, 2019).

\section{A Proposta de Emenda à Constituição (PEC) 15/2015, da deputada Professora Dorinha Seabra Rezende (DEM-TO), e a contraproposta apresentada pelo Governo Federal}

Estudos do Dieese (2020) apontam que o fim do Fundeb poderá prejudicar o financiamento da educação básica de cerca de $92 \%$ dos estudantes em escolas municipais no Brasil. Mais de 3.700 Municípios teriam seus investimentos em educação básica reduzidos, e 20,7 milhões de estudantes da educação básica em escolas municipais seriam prejudicados, o que corresponderia a aproximadamente 94\% dos estudantes das escolas municipais. Só em 2019, dos $\mathrm{R} \$ 248$ bilhões aplicados nas escolas públicas do país, 65\% do total saíram do Fundeb. O fundo recolhe verbas públicas e reparte o montante entre todas as 26 redes estaduais (mais a do Distrito Federal) e as 5.570 redes municipais de ensino. Com o modelo de distribuição, chegamos a um valor de aproximadamente $\mathrm{R} \$ 150$ bilhões investidos em 2019, diante dos $\mathrm{R} \$ 35$ bilhões do Fundef, programa que vigorou até 2006, seu último ano de vigência.

O Fundeb não pode ficar na dependência da conjuntura política para a sua aprovação. É necessário que seja uma política constitucional e permanente para 
Revista Educação e Políticas em Debate - v. 10, n. 1, p. 262-279, jan./abr. 2021 - ISSN 2238-8346 seguirmos com um planejamento de longo prazo na educação. A trajetória da PEC 15/2015 passa pela aprovação na Câmara Federal e segue para o Senado Federal, transformando-se na PEC 26/2020, aprovada no dia 26 de agosto de 2020, a Emenda Constitucional $\mathrm{n}^{\circ}$ 108/2020, que, apesar de representar uma grande vitória, não é suficiente para a garantia do financiamento da educação básica a partir do ano de 2021 , considerando que depende ainda da aprovação da lei que regulamenta o Fundeb.

A PEC 15/2015 recebe o substitutivo da deputada Professora Dorinha Seabra Rezende no dia 18 de fevereiro de 2020, que, em seu relatório, propõe um Fundeb permanente a constar nas Disposições Permanentes da Constituição da República (Art. 212-A). O texto apresentado pela relatora propõe a Complementação da União correspondente a $20 \%$ do total dos recursos de contribuição dos Estados e Municípios ao Fundeb, que atualmente é de 10\%. A proposição é começar com um percentual de 12,5\% no primeiro ano, atingindo os $20 \%$ em 2026, no sexto ano.

O relatório apresenta também a proposição de um modelo híbrido de complementação da União, com uma nova regra distributiva que preserva a distribuição no âmbito dos fundos estaduais e cria duas modalidades de complementação da União: a) até 10\% mantém a mesma regra atual, sem perdas para quem já recebe (equalização estadual); b) a partir daí, adota-se o VAAT (Valor Aluno Ano Total), iniciando com 7,5\%, e a evolução significativa dos indicadores de atendimento e melhoria da aprendizagem, com redução das desigualdades em 2,5\% para a distribuição, com o final de $15 \%$ e de $20 \%$ após seis anos (FERREIRA, 2020).

No modelo, considerado híbrido, a distribuição será por redes estaduais e municipais de ensino. No que se refere à proposta de inclusão do salário-educação para complementação da União, a Associação Nacional de Pesquisadores em Financiamento da Educação (FINEDUCA, 2020) define o uso dos recursos do salário-educação como um “desastre”. Em nota técnica, produziu cálculos mostrando que a aventada nova complementação da União de $20 \%$ ao fundo seria artificial, caso se usassem os recursos do salário-educação, tendo em vista que os recursos do salário-educação já são destinados à educação básica.

Tendo por base as discussões, a relatora, a deputada Professora Dorinha (DEM), retirou a proposição de inclusão do salário-educação. Outro ponto colocado no relatório que merece bastante atenção e que foi muito criticado é a distribuição de recursos a partir de critérios de desempenho, ou seja, relacionando o financiamento da educação aos resultados produzidos pelos entes federados, considerado pela Fineduca como inaceitável, tendo em vista que as consequências dessa relação têm um "alcance duvidoso" na perspectiva da garantia da "evolução significativa dos indicadores de atendimento e de melhoria da aprendizagem com redução das desigualdades”, como também a dificuldade que será 
Revista Educação e Políticas em Debate - v. 10, n. 1, p. 262-279, jan./abr. 2021 - ISSN 2238-8346 mensurar dados de desempenho anualmente no nível dos Municípios. Essa perspectiva pode prejudicar as redes de ensino das localidades cujos estudantes têm situação socioeconômica mais desfavorável, o que vai na contramão da promoção da equidade (FINEDUCA, 2020).

Os recursos do Fundeb devem ser preservados para a educação básica pública. O art. 213 da Constituição da República, reforçado pela Lei de Diretrizes e Bases da Educação (LDB), Lei n ${ }^{\circ}$ 9.394/1996, determina que os recursos públicos sejam dirigidos à educação pública e, ainda, a continuidade da subvinculação de um percentual dos recursos do Fundeb para remuneração dos profissionais da educação, aumentando de no mínimo 60\% para 70\% dos recursos investidos em remuneração.

Às vésperas da votação na Câmara dos Deputados, o governo federal apresentou um outro substitutivo à PEC 15/2015, proposta encaminhada aos líderes partidários na Câmara dos Deputados pela equipe do Ministério da Economia e do Ministério da Educação para o Novo Fundeb. Em síntese, conforme a Fineduca (2020): 1) o Fundeb atual tem vigência até o final de 2020; a proposta do governo federal previa que o novo Fundeb passasse a vigorar somente a partir de janeiro de 2022, deixando o ano de 2021 sem a subvinculação constitucional, impossibilitando o financiamento da educação básica no Brasil a partir da aplicação destinada dos recursos do fundo, criando um colapso e uma paralisia da educação no país, principalmente para Estados e Municípios mais pobres; 2) o atual texto proposto para a PEC 15/2015 prevê a ampliação da complementação do governo federal de 10\% para $20 \%$ ao longo de seis anos. A proposta do governo federal, por sua vez, propõe que, desses dez pontos percentuais de acréscimo, cinco pontos percentuais sejam destinados não à educação pública, mas a programas de transferência de renda, o que ataca frontalmente a vinculação constitucional, sendo avaliado como ilegal e inconstitucional retirar recursos da educação para outros fins. Tal proposta representa um claro desvirtuamento do propósito do Fundeb, além de uma perda de $50 \%$ dos recursos novos a serem complementados pela União no novo Fundeb; e 3) o atual texto da PEC n. 15/2015 estabelece que no mínimo 70\% dos recursos do Fundeb sejam gastos com a remuneração dos profissionais de educação, quando atualmente o percentual permitido é de no mínimo 60\% para professores. O governo federal propõe, no lugar de um percentual mínimo, um limite de 70\% com gastos com a remuneração dos profissionais da educação com recursos do Fundeb, o que inviabiliza o pagamento dos profissionais da educação em várias redes estaduais e municipais, que já destinam um percentual superior a $70 \%$ para esse fim. As pesquisas sobre remuneração docente apontam que os Estados e Municípios aplicam percentuais equivalentes a $80 \%$ e 90\% dos recursos do fundo para a remuneração; 4) a proposta do governo federal permite que recursos públicos da União, dos Estados e dos Municípios sejam utilizados como um auxílio para pagamentos nas 
Revista Educação e Políticas em Debate - v. 10, n. 1, p. 262-279, jan./abr. 2021 - ISSN 2238-8346 redes privadas. É inadmissível a proposta apresentada, sendo necessária uma grande mobilização nacional em favor da educação pública básica e a aprovação do relatório da PEC/15 como proposta de discussão plural, desconsiderando completamente a proposição tardia e sem nenhum compromisso com a educação básica pública que permita o acesso, a permanência e a qualidade com inclusão social, igualdade e equidade.

\section{Aprovação da PEC 15/2015 (Câmara Federal) e da PEC 26/ (Senado Federal): Emenda Constitucional $n^{\circ} 108 / 2020$}

Enfim houve a aprovação, na Câmara dos Deputados, da PEC 15/2015, no dia 20 de julho de 2020, do Novo Fundeb, que será implementado a partir de 2021. Após longa discussão em Comissão Especial, nas várias instâncias da sociedade, a partir das representações da Campanha Todos Pela Educação, Fineduca, CNTE, Anpae, Anped, Consed, Undime, entre outros, o texto aprovado pela Câmara dos Deputados reserva o mecanismo redistributivo proposto pela relatora, deputada Professora Dorinha Seabra Rezende. É importante esclarecer que antes da votação na Câmara Federal o governo retirou o seu substitutivo.

Conforme o relatório aprovado (CÂMARA FEDERAL, 2020.a), a PEC 15/2015 introduz no art. 212-A, inciso I, da Constituição Federal de 1988, em seu corpo permanente, no âmbito de cada Estado e do Distrito Federal, a instituição de um Fundo de Manutenção e Desenvolvimento da Educação Básica e de Valorização dos Profissionais da Educação (Fundeb), com o intuito de destinar parte dos recursos a que se refere o caput do art. 212 à manutenção e ao desenvolvimento do ensino na educação básica e à remuneração condigna de seus profissionais.

$\mathrm{Na}$ cesta de impostos que integra os fundos em cada estado são mantidos os $20 \%$ dos mesmos impostos do Fundeb atual, observadas as ponderações referidas na alínea "a" do inciso X e no $\S 2^{\circ}$ (inciso III). O relatório aprovado pela Câmara Federal aponta os seguintes princípios: equidade e qualidade; transparência; complementação da União e custo aluno qualidade.

No que se refere à equidade e à qualidade, propõe novas ponderações que considerem os educandos dos mais baixos níveis socioeconômicos e a arrecadação tributária das localidades, e acolhe preocupação com a qualidade e o desempenho com equidade. Desse modo, prevê a distribuição de, no mínimo, dez pontos percentuais da cota municipal do ICMS com base em indicadores de melhoria nos resultados de aprendizagem e de aumento da equidade. Os Estados deverão criar leis próprias para essa normatização. Atualmente, Ceará, Pernambuco, Sergipe, Acre, Amapá e Alagoas já possuem essas leis, estando previsto o prazo de até dois anos para que os outros Estados as adotem. É previsto também que parte 
Revista Educação e Políticas em Debate - v. 10, n. 1, p. 262-279, jan./abr. 2021 - ISSN 2238-8346 da complementação da União, a partir de determinado patamar, seja distribuída conforme critérios de aferição da qualidade (CÂMARA DOS DEPUTADOS, 2020.a).

O texto prevê a transparência a partir da disponibilização de informações e dados contábeis, orçamentários e fiscais, de forma a garantir a rastreabilidade, a comparabilidade e a publicidade aos dados coletados. Lei específica disporá sobre normas de fiscalização, avaliação e controle das despesas com educação nas esferas estadual, distrital e municipal.

No que se refere à complementação da União em um modelo híbrido, o percentual do total de recursos aportados por Estados, Distrito Federal e Municípios é ampliado de no mínimo 10\% para, no mínimo, 23\%, a serem distribuídos segundo três modalidades, adotando-se o chamado modelo híbrido de complementação (inciso V): 1) 10 pontos percentuais "no âmbito de cada Estado e do Distrito Federal, sempre que o valor anual por aluno (VAAF) ${ }^{5}$, decorrente da distribuição dos recursos aportados por Estados, Distrito Federal e Municípios, não alcançar o mínimo definido nacionalmente (alínea “a”);" 2) 10,5 pontos percentuais, no mínimo, em cada rede pública de ensino municipal, estadual ou distrital, sempre que o valor anual total por aluno $(\mathrm{VAAT})^{6}$ não alcançar o mínimo definido nacionalmente (alínea "b”); 3) 2,5 pontos percentuais investidos nas redes públicas que, uma vez cumpridas condicionalidades de melhoria de gestão previstas em lei, tenham alcançado evolução de indicadores, a serem definidos, de atendimento e melhoria da aprendizagem com redução das desigualdades, nos termos do sistema nacional de avaliação da educação básica (alínea “c”) (CÂMARA DOS DEPUTADOS, 2020.a).

Assim, o Fundeb terá quatro critérios no modelo híbrido de complementação momentos integrados 1- a; 1-b; 1-c; e 2-a. Os objetivos desses critérios são os seguintes: 1-a) equalizar o VAAF no âmbito dos fundos de cada Estado com seus Municípios (FundebEstados); 1-b) equalizar o VAAF nacionalmente nos Estados e em seus Municípios (complementação-VAAF); 1- c) equalizar o VAAT nacionalmente nas redes de ensino (complementação-VAAT); e 2- a) obter resultados educacionais nas redes de ensino (denominado como critério VAAR resultado (complementação-VAAR). Com exceção da complementação e/ou transferência por resultados, os outros três devem considerar as diferenças e as ponderações entre etapas, modalidades, jornada, estabelecimentos e insumos necessários para a garantia de sua educação de qualidade.

\footnotetext{
${ }_{5}$ Trata-se de critério atualmente utilizado, que considera na apuração do valor por aluno somente as receitas integrantes do Fundeb, porém com a adoção de novas ponderações com uso de indicadores, a fim de corrigir distorções existentes e tornar a distribuição mais equitativa. (CẨMARA FEDERAL, 2020).
} 
Revista Educação e Políticas em Debate - v. 10, n. 1, p. 262-279, jan./abr. 2021 - ISSN 2238-8346

No novo Fundeb, ampliou-se a complementação pela União aos Estados, ao DF e aos Municípios de 10\% para 23\%, numa escala gradativa a partir de 2021 até 2026. Dos recursos dessa complementação, 5\% serão destinados à educação infantil. Um total de 2.745 Municípios serão beneficiários dessa nova complementação de recursos (CÂMARA FEDERAL, 2020.a).

No que se refere à destinação dos recursos do Fundeb, a Câmara Federal (2020) aprovou três subvinculações, que são as seguintes: 1) mínimo de $70 \%$ de cada fundo, no âmbito dos Estados e do Distrito Federal, excetuadas transferências recebidas pela complementação-VAAR, destinados ao pagamento dos profissionais da educação básica em efetivo exercício (inciso XI); 2) 15\%, no mínimo, da complementação-VAAT destinado, por cada uma das redes de ensino beneficiadas, a despesas de capital (inciso XI); 3) 50\% dos recursos globais da complementação VAAT destinados à educação infantil $\left(\S 3^{\circ}\right)$.

O Custo Aluno Qualidade (CAQ) será a referência para o padrão de qualidade preconizado no art. 211 da Constituição Federal de 1988. A LDB (9.394/1996) e o Plano Nacional de Educação - PNE (2014-2024) estabelecem que deva existir um padrão mínimo de qualidade para as instituições de ensino. A Campanha Nacional pelo Direito à Educação defendeu que o CAQ seja a referência de cálculo do novo Fundeb, a fim de evitar distorções entre escolas ao estabelecer "condições equitativas de oferta do ensino". O indicador criado pela campanha é uma das estratégias da Meta 20 do PNE como parâmetro de financiamento (FINEDUCA, 2020.a).

Após a aprovação da PEC 15/2015 na Câmara dos Deputados, o relatório foi encaminhado ao Senado Federal, passando a ser a PEC 26/2020, com relatoria do senador Flávio Arns (Rede-PR), que apresentou o relatório da proposta de Emenda à Constituição (PEC 26/2020) para a manutenção do Fundeb, aprovado sem alterações em relação ao que foi aprovado pela Câmara, transformando-se na Emenda Constitucional $\mathrm{n}^{\mathrm{o}}$ 108, de 26 de agosto de 2020, com a seguinte redação: "Altera a Constituição Federal para estabelecer critérios de distribuição da cota municipal do Imposto sobre Operações Relativas à Circulação de Mercadorias e sobre Prestações de Serviços de Transporte Interestadual e Intermunicipal e de Comunicação (ICMS), para disciplinar a disponibilização de dados contábeis pelos entes federados, para tratar do planejamento na ordem social e para dispor sobre o Fundo de Manutenção e Desenvolvimento da Educação Básica e de Valorização dos Profissionais da Educação (Fundeb); altera o Ato das Disposições Constitucionais Transitórias; e dá outras providências” (BRASIL, 2020).

A Emenda Constitucional 108/20 torna permanente o Fundeb, porém ainda se faz necessária a regulamentação da Lei do Fundeb que, de acordo com a legislação atual, perde a validade no dia 31 de dezembro deste ano. 
Revista Educação e Políticas em Debate - v. 10, n. 1, p. 262-279, jan./abr. 2021 - ISSN 2238-8346

\section{Considerações finais}

O financiamento da educação básica ganhou notoriedade a partir da política de fundos, decorrente da política de financiamento para a educação básica na década de 1990 . Em um primeiro momento, com a aprovação do Fundo de Manutenção e Desenvolvimento do Ensino Fundamental e de Valorização do Magistério (Fundef) e, posteriormente, com o Fundo de Manutenção e Desenvolvimento da Educação Básica Pública e de Valorização dos Profissionais da Educação Básica (Fundeb).

O primeiro dos recursos vinculados da educação, explicitados no art. 212 da Constituição Federal de 1988 para MDE, conforme a Emenda Constitucional n ${ }^{\circ}$ 14, aprovada em 12 de setembro de 1996, subvinculou 60\% dos recursos vinculados de Estados e Municípios para o ensino fundamental e também criou o Fundef, que atendia apenas ao ensino fundamental. A emenda estabeleceu ainda que uma proporção não inferior a $60 \%$ dos recursos de cada fundo estadual seria destinada ao pagamento dos professores do ensino fundamental em efetivo exercício no magistério. O Fundef foi regulamentado pela Lei $n^{\circ}$. 9.424/96. Em 2006, foi aprovada a Emenda Constitucional $\mathrm{n}^{\mathrm{o}} 53 / 06$, que criou o Fundeb, regulamentada pela Lei $\mathrm{n}^{\circ} 11.494 / 07$, a qual ampliou a aplicação dos recursos do fundo para outras etapas da educação básica, a educação infantil, o ensino médio e todas as modalidades do ensino, a exemplo da Educação de Jovens e Adultos (EJA) e da educação profissional.

O Fundeb é o Fundo de Manutenção e Desenvolvimento da Educação Básica e de Valorização dos Profissionais da Educação Básica. É um fundo especial, de natureza contábil e de âmbito estadual (um fundo por Estado e Distrito Federal) de um total de 27 fundos, formado, na quase totalidade, por recursos provenientes de impostos e transferências dos Estados, do Distrito Federal e dos Municípios, vinculados à educação por força do disposto no art. 212 da Constituição Federal. Haverá a complementação de $10 \%$ da União (uma parcela de recursos federais) sempre que, no âmbito de cada Estado, seu valor por aluno não alcançar o mínimo definido nacionalmente. Independentemente da origem, todo recurso gerado é redistribuído para aplicação exclusiva na educação básica. As principais mudanças da Emenda Constitucional nº 53, de 2006, em relação ao Fundef foram: validade de 14 anos, em vez de dez; atendimento a todas as matrículas da educação básica, incluindo educação infantil, ensino médio e EJA; aumento do percentual de impostos para $80 \%$ dos $25 \%$ (ou seja, $20 \%$ da arrecadação), incluindo também o IPVA e o Imposto sobre Transmissão Causa Mortis (ITCD); garantia de montantes crescentes de complementação da União, chegando em 2009 a $10 \%$ da receita total dos fundos; 
Revista Educação e Políticas em Debate - v. 10, n. 1, p. 262-279, jan./abr. 2021 - ISSN 2238-8346 implantação do Piso Salarial Profissional Nacional para os profissionais do magistério público da educação básica (PSPN) definido na forma da Lei $\mathrm{n}^{\circ} 11.738$, de 16 de julho de 2008, com recursos do Fundeb, dos outros impostos (IRRF, IPTU, ISS e ITBI) e do auxílio emergencial do MEC ao ente que comprove sua incapacidade de pagamento.

O Fundeb desempenha uma importante função, que é a de corrigir desigualdades econômicas, garantindo recursos mínimos a partir do custo aluno/ano. Conforme o artigo 48 da lei do Fundeb, definiu-se o final da vigência do fundo para dezembro de 2020. Após aprovações das PECs 15/2015 e 26/2010 na Câmara Federal e no Senado Federal, respectivamente, a Emenda Constitucional 108 passa a regular o Fundeb permanente como uma política de Estado, compondo as Disposições Permanentes da Constituição Federal de 1988, deixando de ser uma política transitória.

A aprovação da Emenda Constitucional 108/2020 (BRASIL, 2020) definiu, conforme o art. 211 , o padrão mínimo de qualidade de que trata o $\$ 1^{\circ}$ desse artigo, que considerará as condições adequadas de oferta e terá como referência o Custo Aluno Qualidade (CAQ), pactuado em regime de colaboração na forma disposta em lei complementar, conforme o parágrafo único do art. 23 da Constituição.

Conforme o art. $212, \S 7^{\circ}$, é vedado o uso dos recursos do Fundeb para o pagamento de aposentadorias e de pensões, e segundo o $\$ 9^{\circ}$, a lei disporá sobre normas de fiscalização, de avaliação e de controle das despesas com educação nas esferas estadual, distrital e municipal. No art. 212-A consta que os Estados, o Distrito Federal e os Municípios destinarão parte dos recursos a que se refere o caput do art. 212 da Constituição à manutenção e ao desenvolvimento do ensino na educação básica.

No que se refere à subvinculação, será destinado o mínimo de $70 \%$ para a remuneração dos profissionais. A União complementará os recursos dos fundos a partir do modelo híbrido que será equivalente a, no mínimo, 23\% do total de recursos a que se refere o inciso II do caput desse artigo, distribuída da seguinte forma: a) 10 (dez) pontos percentuais no âmbito de cada Estado e do Distrito Federal, sempre que o valor anual por aluno (VAAF), nos termos do inciso III do caput desse artigo, não alcançar o mínimo definido nacionalmente; b) no mínimo, 10,5 (dez inteiros e cinco décimos) pontos percentuais em cada rede pública de ensino municipal, estadual ou distrital, sempre que o valor anual total por aluno (VAAT), referido no inciso VI do caput desse artigo, não alcançar o mínimo definido nacionalmente; c) 2,5 (dois inteiros e cinco décimos) pontos percentuais nas redes públicas que, cumpridas condicionalidades de melhoria de gestão previstas em lei, alcançarem evolução de indicadores a serem definidos, de atendimento e melhoria da aprendizagem com redução das desigualdades, nos termos do sistema nacional de avaliação da educação básica. 
Revista Educação e Políticas em Debate - v. 10, n. 1, p. 262-279, jan./abr. 2021 - ISSN 2238-8346

A complementação será distribuída da seguinte maneira: I - 12\% (doze por cento) no primeiro ano; II - 15\% (quinze por cento) no segundo ano; III - 17\% (dezessete por cento) no terceiro ano; IV - 19\% (dezenove por cento) no quarto ano; V - 21\% (vinte e um por cento) no quinto ano; VI - 23\% (vinte e três por cento) no sexto ano. $\mathrm{O} \S 1^{\circ}$, que fala sobre a parcela de complementação de que trata a alínea "b" do inciso V do caput do art. 212-A da Constituição Federal afirma que se observará, no mínimo, os seguintes valores: I - 2 pontos percentuais no primeiro ano; II - 5 pontos percentuais no segundo ano; III - 6,25 pontos percentuais no terceiro ano; IV 7,5 pontos percentuais no quarto ano; $\mathrm{V}-9$ pontos percentuais no quinto ano; e VI - 10,5 pontos percentuais no sexto ano. $\mathrm{O} \S 2^{\circ}$, por sua vez, que fala sobre a parcela da complementação de que trata a alínia "c" do inciso V do caput do art. 212-A da constituição Federal assevera que se observarão os seguintes valores: I - 0,75 ponto percentual no terceiro ano; II - 1,5 ponto percentual no quarto ano; III -2 pontos percentuais no quinto ano; e IV - 2,5 pontos percentuais no sexto ano (BRASIL, 2020).

Encontram-se, no Congresso Nacional, dois projetos de lei: o Projeto de Lei (PL) 4.372/2020, apresentado pela deputada Professora Dorinha Seabra Rezende (DEM-TO), na Câmara Federal, e o Projeto de Lei (PL) 4.519/2020, apresentado pelo senador Randolfe Rodrigues (Rede-AP) no Senado Federal. Diante de todo o exposto, a regulamentação do Fundeb em uma lei se faz urgente, para que no ano de 2021 se tenham garantidos os recursos para a promoção de uma educação básica de qualidade e socialmente referenciada a partir da aprovação do Custo Aluno Qualidade.

\section{Referências}

BRAGA, Daniel Santos; SILVA, Débora Cristina Alves da. Repercussões do FUNDEB em municípios mineiros: aportes para a discussão sobre FUNDEB permanente. Fineduca, Porto Alegre, v. 9, n. 3, 2019. DOI: https://doi.org/10.22491/fineduca-2236-5907-v9-88585.

BRASIL. Constituição da República Federativa do Brasil. São Paulo: Saraiva, 1988.

BRASIL. Emenda Constitucional $N^{\circ} 108$ de 26 de agosto de 2020. Disponível em: http://www.planalto.gov.br/ccivil_03/constituicao/emendas/emc/emc108.htm.

Acesso em 15 out. 2020.

BRASIL. Lei $\mathbf{N}^{\circ}$ 9.424, de 24 de dezembro de 1996. Dispõe sobre o Fundo de Manutenção e Desenvolvimento do Ensino Fundamental e de Valorização do Magistério, na forma prevista no art. 60 do ADCT, e dá outras providências. Brasília, 1996.

BRASIL. Ministério da Educação e Cultura. Emenda Constitucional $\mathbf{N}^{\circ} 53$ de 19 de dezembro de 2006. Disponível em: < http://www.mec.gov.br>. Acesso em: 15 out. 2020. 
Revista Educação e Políticas em Debate - v. 10, n. 1, p. 262-279, jan./abr. 2021 - ISSN 2238-8346

CÂMARA DOS DEPUTADOS. A Proposta de Emenda Constitucional (PEC) no $\mathbf{1 5}$, de 2015, foi apresentada pela nobre Deputada Raquel Muniz em 7 de abril de 2015. Documento eletrônico assinado por Professora Dorinha Seabra Rezende (DEM/TO). *CD208155816500*. Disponível em:

https://www.camara.leg.br/proposicoesWeb/prop_mostrarintegra? codteor=1915114\&filen ame=Tramitacao-PEC+15/2015. Acesso em: 21 jul. 2020.

CÂMARA DOS DEPUTADOS. Consultoria de Orçamento e Fiscalização Financeira. PEC 15/2015 Fundeb: texto aprovado na Câmara dos deputados - novo mecanismo redistributivo: resultados esperados, avaliação e proposta de regulamentação. Estudo Técnico n 22/2020. Disponível em: https://www2.camara.leg.br/orcamento-dauniao/estudos/2020. Acesso em: 10 ago. 2020.a.

CANDERÓN, Adolfo Ignácio; POLTRONIERI, Heloisa; BORGES, Regilson Maciel. Os rakings na educação superior brasileira: políticas de governo ou de Estado? Ensaio: aval. pol. públ. educ., Rio de Janeiro, v. 19, n. 73, p. 813-826, out./dez. 2011. DOI:

https://doi.org/10.1590/s0104-40362011000500005.

CURY, Carlos Roberto Jamil. Financiamento da Educação Brasileira: do subsídio literário ao FUNDEB. Educ. Real., Porto Alegre, v. 43, n. 4, p. 1217-1252, out. 2018. DOI:

https://doi.org/10.1590/2175-623684862.

CARNOY, Martin. Estado e Teoria Política. Campinas, Papirus, 1986.

DIEESE. Nota Técnica. Impactos do fim do Fundeb no financiamento da rede de educação básica pública municipal. N. 219. 2020. Disponível

em: https://www.dieese.org.br/notatecnica/2020/notaTec219Fundeb.pdf. Acesso em: jun. 2020.

FERREIRA, Maria Aparecida dos Santos. O FUNDEF e o FUNDEB como política de financiamento para a valorização do magistério: efeitos na carreira e na remuneração dos professores da rede pública estadual de ensino do RN. 2014, 353 f. Tese (Doutorado em Educação) - Universidade Federal do Rio Grande do Norte, Natal, 2014. Disponível em: $<$ https://repositorio.ufrn.br/jspui/bitstream/123456789/19286/1/FUNDEFeFUNDEBPo 1\%C3\%ADtica_Ferreira_2014.pdf>. Acesso em: 04 jul. 2020.

FERREIRA, Maria Aparecida dos Santos. Financiamento da educação básica e o FUNDEB permanente: depoimento. [20 de julho de 2020]. Natal: Potiguar Notícias. Entrevista concedida a Andrezza Tavares.

FERREIRA, Maria Aparecida dos Santos; Oliveira, Edmilson Jovino. Financiamento da educação básica e a remuneração dos profissionais do magistério: aplicação dos recursos do Fundef e do Fundeb na rede pública estadual de ensino do RN (1996-2014). In: FRANÇA, Magna; BARBOSA JUNIOR, Walter Pinheiro (Orgs.). Políticas e práxis educativas. Natal: Caule de Papiro, 2017, p. 120-157.

FINEDUCA- Associação Nacional de Pesquisa em Financiamento da Educação. A PEC do Fundeb e o CAQ como instrumento de controle da aplicação dos recursos educacionais. Disponível em: https://fineduca.org.br/wp-content/uploads/2020/08/PECdo-Fundeb-fiscalizac_a_o-e-CAQ_-vers\%C3\%A30-final-1.pdf. Acesso em: 10 de out. 2020. 
Revista Educação e Políticas em Debate - v. 10, n. 1, p. 262-279, jan./abr. 2021 - ISSN 2238-8346

FINEDUCA. Campanha Nacional pelo Direito à Educação. Atenção: é preciso proteger o financiamento da educação básica dos prejuízos da crise econômica! Disponível em: https://fineduca.org.br/wp-content/uploads/2020/05/20200507_Nota_queda_receitas final.pdf. Acesso em: 10 de out. 2020.a.

FRANÇA, Magna. Financiamento da Educação Básica e o novo Fundeb. Conferência. Educação Políticas e Práticas pedagógicas em tempos de distanciamento físico. Laboratório de Políticas Educacionais. Centro de Educação. UFRN. 2020.

HÖFLING, Eloisa de Mattos. Estado e políticas (públicas) sociais. Cadernos Cedes, Campinas, v. 21, n. 55, p. 30-41, nov. 2001. DOI: https://doi.org/10.1590/s0101-32622001000300003.

KOSIK, Karel. Dialética do concreto. $5^{\text {a }}$ ed. Rio de Janeiro: Paz e Terra, 1976.

MORAIS, Magnólia Margarida dos Santos. Regime de colaboração e o PAR da rede estadual de ensino do RN (2011-2014): a dimensão infraestrutura e recursos pedagógicos. Dissertação (Mestrado em Educação). Universidade Federal do Rio Grande do Norte, Natal, 2020.

PINTO, José Marcelino de Rezende. O financiamento da educação na Constituição Federal de 1988: 30 anos de mobilização social. Educ. Soc., Campinas, v. 39, n. 145, p. 846-869, out./dez. 2018. DOI: https://doi.org/10.1590/es0101-73302018203235.

SENADO FEDERAL. Proposta de Emenda à constituição $\mathbf{n}^{\circ} \mathbf{2 6}$, de $2020\left(\mathbf{n}^{\circ} \mathbf{1 5} / \mathbf{2 0 1 5}\right.$. (Câmara dos Deputados). Avulso da PEC 26/2020. Disponível em: https://legis.senado.leg.br/sdleggetter/documento?dm=8867664\&ts=16022652726668disp osition=inline. Acesso: ago. 2020.

ROJO, Jeferson Roberto et al. Políticas de Estado ou políticas de governo? Uma análise sobre as políticas públicas de corrida de rua em Curitiba-PR. J. Phys. Educ., Maringá, v. 30, n. 1, 2019. DOI: https://doi.org/10.4025/jphyseduc.v30i13062.

ROSA, Sérgio. Reforma da previdência: política de Estado ou política de governo? Res Pvblica, Brasília, v. 2, n. 2, p. 80-98, maio 2003. 